\title{
Continuidad y cambio en las élites políticas locales, de la Restauración a la II República: El caso de Álava
}

\author{
Santiago de Pablo *
}

El problema de la renovación y la continuidad de la élite política en España durante el siglo $x x$ ha sido tratado, entre otros, por el profesor Linz ${ }^{1}$. En este trabajo pretendemos estudiar si las discontinuidades encontradas a nivel nacional (parlamentarios) se repiten también en el ámbito local (diputados provinciales y concejales), y en concreto en la provincia de Álava. Para ello hemos creado una base de datos con los nombres de todos los que ocuparon cargos públicos en Álava desde 1910 - año que hemos tomado como punto de partida para poder comparar resultados con los del profesor Linz - hasta 1936. El hecho de que se trate de una provincia pequeña nos ha permitido un vaciado exhaustivo de los concejales, sin necesidad de recurrir a muestreos ${ }^{2}$. Lógicamente, las peculiaridades de la provincia de Álava (fundamentalmente rural, con escasa modernización económica y con una sociedad todavía

Universidad del País Vasco.

1 Cfr. LINZ, Juan J., "Continuidad y discontinuidad en la élite política española: De la Restauración al régimen actual»", en Estudios de Ciencia Política y Sociología. Homenaje al Profesor Carlos Ollero, Madrid, Gráficas Carlavilla, 1972, págs. 361-423.

2 Faltan, sin embargo, datos de concejales de algunos ayuntamientos: uno de abril de 1931, dos de la Dictablanda, uno de las elecciones de 1920 y varios de las de 1911. Los nombres de los concejales y diputados los hemos obtenido de las actas electorales que se conservan en el Archivo Provincial de Álava, de la prensa local (La Libertad y Heraldo Alavés, 1900-1936) y -para los concejales de la Dictadura- de las listas de compromisarios para la elección de senadores publicadas en el Boletín Oficial de la Provincia de Álava. No citamos las fuentes en cada caso para no aumentar la extensión del artículo. 
fuertemente cohesionada) hacen que no se puedan extender las conclusiones de este trabajo a provincias más desarrolladas.

\section{LA RESTAURACIÓN}

El cuadro que recoge el número de veces que fueron diputados a Cortes o senadores los elegidos por Álava entre 1910 y 1923 muestra una continuidad y renovación semejantes a las generales de España. Los resultados demuestran una escasa renovación de la élite parlamentaria, sobre todo en lo referente a los diputados, donde solo el $33 \%$ fueron elegidos una sola vez. Veintidós puestos de diputados y senadores (incluyendo en ambos casos una elección parcial) se cubrieron respectivamente con sólo nueve y diez personas distintas. Estos datos colocan a Álava dentro de las regiones con menos renovación de sus representantes en Cortes, por debajo de Baleares, pero superando a regiones muy estables, como Navarra, y muy por encima de la media de España y del País Vasco (un 58 y un $54 \%$ de sus diputados, respectivamente, lo fueron una sola vez en el período 1910-1923 ${ }^{3}$ ). Esta continuidad sería todavía mayor si tenemos en cuenta que tres de los elegidos representantes en Cortes ocuparon tanto puestos de senadores como de diputados y que otro más dejó su puesto como senador por Álava al ser nombrado senador vitalicio.

TABLA 1

Número de veces que fueron diputados a Cortes o senadores los elegidos por Álava entre 1910 y 1923

\begin{tabular}{lcccccccc}
\hline & & 6 veces & 5 veces & 4 veces & 3 veces & 2 veces & 1 vez \\
\hline \multirow{2}{*}{ Diputados } & $\mathrm{n} .^{\circ}$ & 1 & 1 & - & - & 4 & 3 \\
\cline { 2 - 8 } & $\%$ & 11 & 11 & - & - & 44 & 33 \\
\hline \multirow{2}{*}{ Senadores } & $\mathrm{n} .^{\circ}$ & 1 & - & 1 & 1 & 2 & 5 \\
\cline { 2 - 8 } & $\%$ & 10 & - & 10 & 10 & 20 & 50 \\
\hline
\end{tabular}

${ }^{3}$ Cfr. L.ıNZ, op. cit., pág. 373. 
La filiación política de los elegidos en varias ocasiones nos puede ayudar a comprender el sentido de la tendencia a la escasa renovación que se observa en los parlamentarios alaveses. Entre los que son elegidos al menos en tres veces predominan los urquijistas y los conservadores y sólo encontramos - a pesar de la fuerza popular del carlismo en Álava - un carlista. El caciquismo ejercido por la familia Urquijo en el distrito de Amurrio (copado por sus representantes durante toda la Restauración) y por Dato en el distrito de Vitoria explican en gran medida la escasa renovación parlamentaria en Álava.

TABLA 2

Número de veces que fueron diputados provinciales por Álava los elegidos entre 1900 y 1923

\begin{tabular}{cccccc}
\hline & 5 veces & 4 veces & 3 veces & 2 veces & 1 vez \\
\hline $\mathrm{n} .{ }^{\circ}$ & 1 & 2 & 1 & 9 & 40 \\
\hline$\%$ & 2 & 4 & 2 & 17 & 75 \\
\hline
\end{tabular}

Para la Diputación - teniendo en cuenta que las elecciones se celebraban bianualmente en la mitad de los distritos- hemos contabilizado las elecciones desde 1900. De este modo, en cada distrito hay seis elecciones (además de las parciales) y podemos comparar estos datos con los de las elecciones a Cortes. Para cubrir setenta y cuatro puestos en este período fueron diputados provinciales cincuenta y tres personas. El $75 \%$ de los diputados lo fueron una sola vez, lo que indica una fuerte renovación, que no se alcanza, por ejemplo, en lo que refiere a diputados a Cortes, en ninguna de las regiones españolas entre 1910 y $1923^{4}$. La causa de esta fuerte diferencia con los diputados a Cortes puede ser tanto el mismo mayor número de puestos a cubrir como la diferente actuación del caciquismo en este tipo de elecciones, no ligadas tanto (como en el caso de las Cortes) a una persona concreta. Así, es significativo que en este caso los elegidos más de tres veces sean un carlista, un integrista, un liberal y tan sólo un urquijista. No obstante, en los últimos años de la Restauración parece cambiar la situación, al aumentar el número de los que repiten puesto en la Diputación, sobre todo entre los urquijistas. Así, en la Diputación que se constituye en el verano de 1923

\footnotetext{
${ }^{4}$ Cfr. ibidem.
} 
siete de sus doce componentes (un $58 \%$ ) tenian experiencia en la Diputación Provincial, proporción mucho mayor que la que se da en años anteriores.

TABLA 3

Número de veces que fueron concejales los elegidos por Álava entre 1910 y 1923

\begin{tabular}{rrrc}
\hline & 1 vez & 2 veces & 3 veces \\
\hline n. & 1389 & 193 & 17 \\
\hline$\%$ & 86 & 12 & 1 \\
\hline
\end{tabular}

Por lo que respecta a los ayuntamientos, es difícil compararlos con otras elecciones, puesto que el número de comicios es menor (seis entre 1910 y 1923) y la renovación es bienal, por lo que el número máximo de veces que una persona puede ser elegida concejal en el período se reduce a tres. Hubiera sido interesante añadir algunos años anteriores para tener un mayor número de elecciones. De todas formas, como conclusión provisional podemos adelantar que la renovación de las élites a nivel local es mucho mayor que a nivel provincial y de diputados a Cortes: el $86 \%$ de los concejales lo fueron una sola vez y los mil ochocientos veintiséis puestos que salieron a elección entre 1910 y 1923 fueron cubiertos por mil quinientas noventa y nueve personas distintas. En los ayuntamientos constituidos en 1922 sólo un $21 \%$ de sus componentes tenían experiencia municipal en los últimos doce años. En Vitoria, esta proporción se elevaba hasta un $31 \%$, lo que parece indicar cierta tendencia a una mayor continuidad en la capital que en la zona rural. Es posible - aunque pueda parecer en principio paradójico- que la propia crisis del sistema de la Restauración explique esta movilidad, que puede llegar incluso a ser tan peligrosa para la salud del sistema político como la excesiva continuidad de carácter oligárquico. Hubiera sido interesante - aunque hemos tenido que renunciar a ello por falta de tiempo- estudiar estos prorcentajes de continuidad según la población de los municipios, así como la incidencia que sobre aquélla pudo tener el artículo 29 de la ley electoral de 1907.

Podemos concluir por tanto - a falta de estudios sobre un período de tiempo más amplio de la Restauración- que en el reinado de Alfonso XIII en Álava la movilidad de la élite es mayor en los ámbitos locales y municipales que en la Diputación Provincial y en los represen- 
tantes a Cortes, donde por el contrario abundan las continuidades producidas por el caciquismo personalista de algunos líderes políticos o familias de notables.

\section{LA DICTADURA DE PRIMO DE RIVERA}

Como ha afirmado Linz, la Dictadura de Primo de Rivera desplazó, al menos a nivel nacional, la clase política de la Restauración ${ }^{5}$. En Álava se cumple también esta afirmación, tanto en lo que se refiere a los representantes parlamentarios como a la Diputación Provincial. De los tres representantes alaveses en la Asamblea Nacional, ninguno había sido diputado o senador antes de 1923. De los quince diputados provinciales de la Dictadura en Álava sólo uno (un carlista) había sido diputado provincial durante la Restauración. La proporción, un $6 \%$, es incluso menor de la del número de diputados o senadores de la Restauración presentes en la Asamblea Nacional (16\%), lo que implica una drástica renovación de la clase política alavesa, que puede sorprender aún más por tratarse de una provincia política y socialmente conservadora.

TABLA 4

Experiencia política de los concejales de la Dictadura en Álava

\begin{tabular}{lcccc}
\hline & $\begin{array}{c}\text { N. }{ }^{\circ} \text { puestos } \\
\text { teóricos }\end{array}$ & $\begin{array}{c}\text { N. }{ }^{\circ} \text { personas } \\
\text { distintas }\end{array}$ & \multicolumn{2}{c}{$\begin{array}{c}\text { Concejales que lo habian sido } \\
\text { en la Restauración }\end{array}$} \\
\hline Zona rural & 591 & 882 & $\mathrm{n}^{\circ}$ & $\%$ \\
\hline Vitoria & 30 & 115 & 188 & 21 \\
\hline Total & 621 & 997 & 10 & 8 \\
\hline
\end{tabular}

En cuanto al poder municipal durante la Dictadura, hay que destacar en primer lugar la diferencia entre la relativa estabilidad de los municipios

${ }^{5}$ Cfr. Linz, op. cit., pág. 375. 
rurales (en bastantes municipios no hubo cambios durante toda la Dictadura y en otros hubo una sola renovación, hacia 1928) frente a la enorme inestabilidad de Vitoria, con ciento quince personas ocupando los treinta escaños teóricos municipales durante cinco años ${ }^{6}$. Por lo que respecta a la continuidad o discontinuidad a nivel local en relación con la Restauración, hay en Vitoria una clara discontinuidad, en la que se refleja el deseo del Gobierno de apartar del poder a los hombres de la "vieja política»: sólo un $8 \%$ de los concejales vitorianos lo habían sido con anterioridad a la Dictadura. Esta brusca discontinuidad es mucho menor en la zona rural, donde el $21 \%$ de los concejales de la Dictadura ya lo habían sido durante la Restauración. Aunque el porcentaje es objetivamente pequeño, si lo comparamos con los ediles de 1922 que tenían experiencia política (también un $21 \%$ ) vemos que propiamente no existe una ruptura ${ }^{7}$. Se puede afirmar que la Dictadura supuso un corte radical en cuanto a la clase política nacional, provincial y de las capitales, pero no produjo grandes discontinuidades en los municipios de las zonas rurales.

\section{DE LA DICTADURA A LA REPÚBLICA: 1930-1931}

El gobierno del general Berenguer, establecido tras la caída del régimen promorriverista, intentó volver a la situación anterior a 1923 y restablecer el régimen constitucional, como si nada hubiera pasado. Este intento estuvo presente en la designación de Ayuntamientos y Diputaciones efectuada en febrero de 1930, tras la dimisión del dictador. La Diputación se constituyó por los diputados más votados antes de 1923 y por representantes corporativos. Por ello, la mitad de los diputados alaveses lo habían sido en la Restauración y ninguno de ellos durante la Dictadura. También es significativo que entre los candidatos que iban a presentarse por Álava en las finalmente fallidas elecciones legislativas convocadas por Berenguer, un $40 \%$ (dos de cinco) hubieran sido diputados a Cortes durante la Restauración y ninguno de ellos hubiera participado en la política alavesa de la Dictadura. Los dos candidatos ex-diputados eran ur-

${ }^{6}$ Para los concejales de Vitoria, cfr. LOPEz S., «Evolución del Ayuntamiento de Vitoria durante la Dictadura de Primo de Rivera, 1923-1930", en Primeras Jornadas de Historia Local, San Sebastián, Sociedad de Estidios Vascos, 1988, vol. II, págs. 691-710.

${ }^{7}$ Lógicamente, estas conclusiones son provisionales, hasta que no podamos incluir en el análisis un número mayor de años de la Restauración. De todas formas, aún contando sólo las elecciones municipales celebradas entre 1910 y 1923 , el dato de experiencia política de los concejales de los últimos ayuntamientos constitucionales de la Restauración parece bastante significativo. 
quijistas, lo que indica un deseo - también por parte de la Casa Urquijo- de volver a la situación política anterior al golpe de Estado de Primo de Rivera.

En cuanto al poder municipal, el Gobierno dispuso que los nuevos ayuntamientos se constituyeran, en su mitad, por los ex-concejales más votados en las elecciones anteriores a 1923, y en el otro $50 \%$ por los mayores contribuyentes del municipio. El porcentaje de ex-concejales de la Restauración en estos ayuntamientos era del $65 \%$ en toda Álava, superior por tanto al $50 \%$ exigido y previsto por el Gobierno. Este hecho demostraba la tendencia existente en la zona rural a ser elegidos concejales los mayores contribuyentes en mayor proporción al resto de la población ${ }^{8}$. Respecto a la continuidad con la Dictadura de Primo de Rivera, el $12 \%$ de los concejales de la Dictablanda lo habían sido ya en el régimen anterior. Si tenemos en cuenta que de estos, un $80 \%$ lo habían sido también durante la Restauración, vemos que las medidas del Gobierno Berenguer supusieron realmente una ruptura con la Dictadura de Primo de Rivera y una clara vuelta atrás, al regresar a los ayuntamientos una parte importante de la clase política de la Restauración.

TABLA 5

Experiencia política de los concejales de la Dictablanda en Álava

N. ${ }^{\circ}$ de Concejales de Concejales de Concejales con conceja- la la experiencia política les Restauración Dictadura

\begin{tabular}{lcccc}
\hline Vitoria & 29 & $55 \%$ & $10 \%$ & $58 \%$ \\
\hline Zona rural & 588 & $65 \%$ & $12 \%$ & $67 \%$ \\
\hline TOTAL & 617 & $65 \%$ & $12 \%$ & $67 \%$ \\
\hline
\end{tabular}

${ }^{8}$ Cfr. Romero, C., Soria. 1860-1936, vol. I, Soria, Diputación Provincial, 1981, pág. 140. En este estudio, Romero señala que en las elecciones de abril de 1931 el $89 \%$ de los concejales electos en los municipios menores de 500 habitantes eran a la vez máximos contribuyentes. Este porcentaje se reducía al $52 \%$ en los municipios de más de 500 habitantes. 


\section{LA SEGUNDA REPÚBLICA}

La falta de continuidad en la clase política de la monarquía constitucional y de la Segunda República fue - según Linz ${ }^{9}$ - " grande, sorprendente y de graves consecuencias". En Álava, esta discontinuidad es clara en lo que se refiere a las elecciones a Cortes y a los nombramientos para la Comisión Gestora de la Diputación. El escaso número de diputados por Álava durante la República (dos por legislatura) permite establecer pocas comparaciones numéricas, pero sí podemos sacar algunas conclusiones: los seis puestos teóricos de diputados por Álava entre 1931 y 1936 son ocupados por cuatro personas diferentes: una de ellas (José Luis Oriol, de la Comunión Tradicionalista) repite en las tres legislaturas, mientras que los otros tres diputados son personas diferentes. Es decir, un $25 \%$ de los diputados por Álava están presentes en las tres Cortes, lo que supone una proporción mucho mayor que en el total de España $(7,3 \%)$ e indica la presencia en Álava de un partido claramente hegemónico - la Comunión Tradicionalista - y con un líder preponderante y absorbente: el propio José Luis Oriol. En el resto de los partidos, se constata la tendencia a ser reelegido candidato cuando se ha triunfado en la elección anterior y a ser reemplazado en cuanto se pierde el puesto parlamentario. De los cuatro diputados por Álava, ninguno lo había sido durante las Cortes de la Restauración ${ }^{10}$, ni en la Asamblea Nacional de Primo de Rivera. Si incluimos a todos los candidatos a diputados durante la República (un total de nueve en las tres elecciones), vemos que ni uno solo de ellos había sido diputado con anterioridad a 1931, ni había ocupado cargo político alguno. En cuanto a la Comisión Gestora de la Diputación, de las 37 personas distintas que ocuparon puestos en ella durante la República, ninguna lo habia sido durante la Dictadura y sólo dos habían ocupado puestos en la Diputación Provincial durante la Restauración. De estos, uno lo había sido también —como diputado más votado antes de 1923 - entre 1930 y 1931 . Es significativo que estos dos únicos diputados con experiencia en la política provincial antes de 1931 fueran antiguos miembros del Partido Liberal que durante la República formaron parte o estuvieron ligados al Partido Republicano Radical, ocupando sus puestos en la Comisión Gestora fundamentalmente durante el bienio 1934-1936. El porcentaje de diputados

${ }^{9}$ Cfr. LiNZ, op. cit., pág. 385.

${ }^{10}$ José Luis Oriol había sido diputado en 1918 por el distrito andaluz de Linares, pero hasta después de la proclamación de la Segunda República no tuvo ninguna relación con la política alavesa. 
provinciales con experiencia política era del $5 \%$, lo que supone --si a ello añadimos la total ruptura que se produjo en los representantes a Cortes- una brusca discontinuidad con la Restauración, que también se produjo a nivel nacional y que en gran parte estuvo motivada por la Dictadura de Primo de Rivera. Como afirma Linz, «no fue la República la que barrió la clase política de la Restauración y la monarquía liberal, sino la Dictadura»" ${ }^{11}$.

\section{TABLA 6}

Experiencia política de los concejales elegidos por Álava en las elecciones municipales de abril de 1931

\begin{tabular}{lrrrrrrrrr}
\hline & \multicolumn{6}{c}{ Concejales que ya lo habian sido en } \\
\cline { 2 - 10 } & Restauración & Dictadura & Dictablanda & $\begin{array}{c}\text { Total con } \\
\text { experiencia }\end{array}$ \\
\hline Vitoria & 8 & $25 \%$ & 3 & $9 \%$ & 6 & $19 \%$ & 12 & $38 \%$ \\
\hline Zona rural & 168 & 31 & $\%$ & 71 & $13 \%$ & 126 & $23 \%$ & 250 & $46 \%$ \\
\hline TOTAL & 176 & 31 & $\%$ & 74 & $13 \%$ & 132 & $23 \%$ & 262 & $46 \%$ \\
\hline
\end{tabular}

Esta discontinuidad no se produjo, por el contrario, en el poder municipal. En las elecciones celebradas en abril de 1931 -dos días antes de la proclamación de la República- un $46 \%$ de los concejales elegidos tenían experiencia política en ayuntamientos anteriores. En especial, era importante la continuidad con la Restauración (un $31 \%$ ), sobre todo teniendo en cuenta que habían pasado ocho años, y también con la Dictablanda e incluso con la Dictadura de Primo de Rivera: el hecho de que un $13 \%$ de los concejales elegidos en 1931 lo hubieran sido durante el período 1923-1930 era significativo, sobre todo teniendo en cuenta que el porcentaje de asambleistas de Primo de Rivera presentes en las Cortes de la Segunda República era ligeramente inferior al dos por ciento. En Vitoria, la renovación de la élite política local era más importante que en la zona rural, pero aún así las continuidades seguían siendo apreciables. En cuanto a los partidos políticos, esta continuidad afectaba a todos ellos: entre los concejales con experiencia política encontramos tanto mo-

${ }^{1}$ Cfr. Linz, pág. 377. 
nárquicos como nacionalistas y republicanos. En estos dos últimos casos se trataba - sobre todo en la zona rural- en bastantes ocasiones de antiguos monárquicos que habían cambiado su ideología política tras la proclamación de la Segunda República.

TABLA 7

Experiencia política de los concejales elegidos por Álava en las elecciones municipales de abril de 1933

\begin{tabular}{cccccc}
\hline & \multicolumn{5}{c}{ Concejales ya elegidos en } \\
\cline { 2 - 6 } & 1931 & Dictablanda & Dictadura & Restauración & $\begin{array}{c}\text { Total con } \\
\text { experiencia } \\
\text { política }\end{array}$ \\
\cline { 2 - 6 } N. $^{\circ}$ & 52 & 20 & 29 & 39 & 103 \\
\hline$\%$ & $20 \%$ & $7 \%$ & $11 \%$ & $15 \%$ & $39 \%$ \\
\hline
\end{tabular}

La situación tampoco cambió especialmente en las elecciones municipales parciales de abril de 1933. Aunque las continuidades eran numéricamente menores - dado que también había pasado más tiempo- hay que destacar que todavía un $15 \%$ había sido concejal durante la Restauración y un $11 \%$ durante la Dictadura. Este último porcentaje es bastante altú si lo comparamos con el $13 \%$ de 1931 , y puede explicarse también por el auge de la derecha en estas elecciones. El índice de renovación con respecto a abril de 1931 es sin embargo relativamente elevado y sólo el $20 \%$ de los concejales de 1933 lo habian sido ya en la elección anterior. Si comparamos estos datos y los de 1931 con los de experiencia política en las últimas elecciones municipales de la Restauración (donde sólo el $21 \%$ habían sido concejales anteriormente), vemos que hay una clara continuidad ${ }^{12}$. Lo mismo sucede al comparar estos porcentajes con los de diputados en las Cortes de la República que habían sido representantes en las Cortes de la Restauración: un $11 \%$, inferior al que se produce en los ayuntamientos alaveses tanto en 1931 (dos días antes del cambio de régimen) como en 1933. Esta relativa continuidad se observa también en el estudio de la Comisión Gestora del Ayuntamiento de Vitoria nombrada por el Gobierno en septiembre de 1934 para sustituir a

${ }^{12}$ Como ya hemos señalado, estos resultados estarian pendientes de confirmación por una investigación de los resultados de las elecciones municipales anteriores a 1910. 
los concejales vitorianos destituidos como consecuencia del pleito del Estatuto del Vino. Un $33 \%$ de estos concejales ya lo habían sido en la Restauración, y un $14 \%$ durante la Dictadura de Primo de Rivera. Se trata de un Ayuntamiento en el que el Partido Radical es el grupo político predominante. Ello indica que - como en la Gestora provincial- el Partido Radical es el que recoge fundamentalmente la tradición liberal de la Restauración.

\section{CONCLUSIÓN}

Como conclusión de este estudio - y a falta de resultados más profundos que podrían extraerse estudiando un mayor número de años de la Restauración a nivel municipal- podemos afirmar que la élite política nacional (representantes en Cortes) se renueva muy poco a lo largo de la Restauración y sufre sin embargo grandes discontinuidades - ya señaladas por Linz para toda España - con motivo de los cambios políticos del período: Dictadura de Primo de Rivera y Segunda República. En la Diputación de Álava encontramos una mayor tendencia a la renovación durante la Restauración, pero también las mismas discontinuidades en la sustitución de una élite política por otra en el tránsito de la Restauración a la Dictadura y de ésta - tras el paréntesis de la Dictablanda- a la República.

A nivel municipal, por el contrario, las élites políticas locales se renovaron con bastante rapidez durante los últimos años de la Restauración. Esta mayor renovación de los cuadros políticos a nivel local que a nivel nacional puede parecer sorprendente pero, por ejemplo, fue señalada también por Linz para la España de Franco, a pesar de que esta conclusión era calificada por él mismo como inesperada, dado lo previsible de una mayor continuidad oligárquica a nivel local. El grado de renovación de la élite política en Álava se mantuvo bastante estable con relativa independencia de los cambios de régimen político del período 1910-1936. La Dictadura de Primo de Rivera supuso la mayor ruptura de élites a nivel local, puesto que en las elecciones de 1931 y 1933 hubo un mayor porcentaje de antiguos concejales de la Restauración y de la Dictadura que en ésta con respecto a la Monarquía Constitucional. Sería interesante comprobar si la situación a nivel local se mantuvo - al menos en una provincia conservadora y que apoyó mayoritariamente el nuevo régimen, como fue el caso de Álava - tras la instauración del régimen franquista, o si por el contrario se produjo una renovación drástica o una relativa vuelta de las élites de la Dictadura de Primo de Rivera, como la 
que tuvo lugar a nivel parlamentario en las Cortes franquistas de la posguerra. Pero esta comparación no es posible hacerla por el momento, dado el estado actual de nuestros conocimientos sobre la clase política del franquismo en Álava ${ }^{13}$.

${ }^{13}$ De los 14 diputados provinciales nombrados por el nuevo régimen entre agosto y noviembre de 1936, uno lo había sido durante la Dictadura y la Restauración y otros dos durante la Restauración. Adernás, esta Diputación estaba formada por otras personas que habían sido concejales o habian ocupado cargos internos en la Comunión Tradicionalista durante la Segunda República. De los 19 concejales nombrados para el Ayuntamiento de Vitoria entre agosto y octubre de 1936, sólo uno había sido concejal durante la Dictadura y ninguno durante la Restauración o la República. Otro había sido elegido concejal en abril de 1931, pero su acta fue impugnada y no llegó a tomar posesión del cargo. Hubo por tanto una clara discontinuidad en el Ayuntamiento de Vitoria, aunque habría que estudiar los años posteriores. De algunos datos aislados de ayuntamientos rurales nombrados en plena Guerra Civil se desprende que persiste una cierta continuidad, con algunos ex-concejales de la Dictadura y otros de la Restauración, junto a una mayoría de personas sin experiencia política. Sin embargo, habría que disponer de datos de un mayor número de ayuntamientos y de años posteriores a la Guerra para poder elaborar una hipótesis más sólida. 